\title{
Methodology of Bending of RC Beams with Opening for the Usage in Construction Engineering Management
}

\author{
Ahmed Abdel Hamid Abdallah* \\ Civil Engineering Department at the MTI - University, Egypt
}

Submission: August 08, 2017; Published: August 31, 2017

*Corresponding author: Ahmed Abdel Hamid Abdallah, Assistant Professor at the Civil Engineering Department at the MTI - University, Cairo, Egypt, Tel: +201007090069; Email: drahmeda@hotmail.com

\begin{abstract}
In this methodology for providing an opening in beam develops cracks around the opening due to stress concentration. In this analysis an experimental works conducted to study the behavior of RC beam with different shapes of opening with varying diameters at different locations. This investigation presents the behavior of RC beam with opening unstrengthened by additional reinforcement. In this experimental study over twenties beams were casted, one beam (BN) without opening as a control beam and the remaining beams were provided with opening. These beams were tested under four point loading. The effect of size of opening with different settings was studied in terms of ultimate failure load, maximum deflection and failure has been mode. From the test results, it could be concluded that the ultimate load carrying capacity of the RC beam at shear zone with opening was maximum reduction but at flexure zone showed minimum reduction. Rectangular opening increased the ultimate load reduction than square opening by $(3 \%)$, while the circular opening reduced the ultimate load reduction than square opening by (6\%).
\end{abstract}

Keywords: Construction engineering management; Shear and flexural behavior; RCbeams, circular opening; Depth of beams web opening effect; Rectangular opening

\section{Introduction}

Utility pipes and ducts are necessary to accommodate essential services in a building. The types of services include airconditioning, power supply, telephone line, computer network, sewerage and water supply. It has been practiced that pipes and ducts are usually hanged below the floor beams, and covered by a suspended ceiling for its aesthetic purpose. These openings can be of different shapes and sizes as circular, square or rectangular [1].

The presence of an opening in the web of a reinforced concrete beam leads to many problems in the beam behavior such as reduction in the beam stiffness, excessive cracking, excessive deflection and reduction in the beam strength [2-4]. Furthermore, sudden change in the dimension of cross section of the beam leaded to high stress concentration at the corners of opening that may lead to cracking unacceptable from aesthetic and durability viewpoints. The reduced stiffness of the beam may also give rise to excessive deflection under service load and result in a considerable redistribution of internal forces and moments in a continuous beam. It has been noted that the classification of opening depended on the structural response of the beam; when the opening is small enough to maintain the beam-type behavior, then the opening could be termed as small opening. Otherwise, large openings are those that prevent beam-type behavior to develop [1,5,6]. A circular opening may be considered as large when its diameter exceeds $40 \%$ of the depth of the web $[3,7,8]$, but square opening considered as large when height exceed quarter of the depth of the web $[9,10]$.

\section{Experimental Investigation}

The tested RC beam specimens were designed according to Egyptian specification code. The nominal value of compressive strength of concrete ( $\mathrm{fc}$ ) is $30 \mathrm{MPa}$. The longitudinal steel reinforcement was steel bars with nominal yield strength (fy) of $360 \mathrm{MPa}$. The stirrups were mild steel with nominal yield strength of $240 \mathrm{MPa}$. In the experimental program, a total of $27 \mathrm{RC}$ beam specimens were tested to failure under four point loading to investigate the behavior including ultimate load, ultimate deflection and failure mode. 


\section{Civil Engineering Research Journal}

\section{Materials}

Ordinary Portland cement (CEM I $42.5 \mathrm{~N}$ ) was used. The water cement ratio was 0.5 . The coarse aggregate was $20 \mathrm{~mm}$ dolomite. Fine sand as fine aggregate was used. The main reinforcement bars was $2 \varnothing 12$ at bottom, and $2 \varnothing 10$ at top. The web reinforcement was closed stirrups of $8 \mathrm{~mm}$ with spacing of $150 \mathrm{~mm}$.

\section{Specimens}
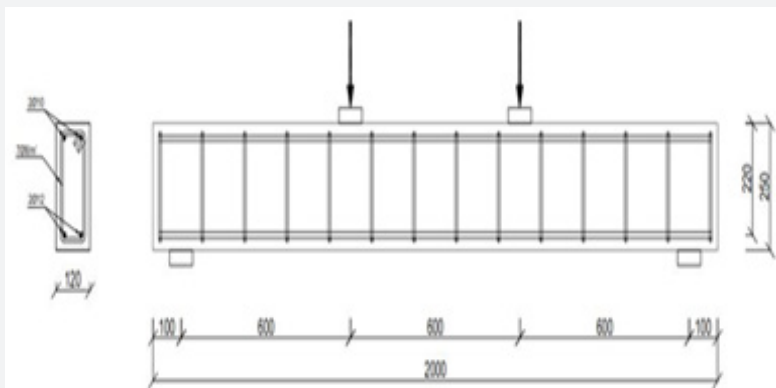

Figure 1: Detail of beam reinforcement with experimental setup.

All the tested beams were rectangular in cross-section having the dimensions width (b) of $120 \mathrm{~mm}$, height $(\mathrm{H})$ of $250 \mathrm{~mm}$ with effective depth (d) of $220 \mathrm{~mm}$. The overall length (L) is $2000 \mathrm{~mm}$ with span length (l) of $1800 \mathrm{~mm}$. Figure (1) and Table (1) give details of the tested beams. The beams were cast in a horizontal position using steel formwork. The circular opening was created by a circular polyvinyl chloride (PVC) pipe inserted in the beam before casting of concrete; whereas, square and rectangular opening was created by inserting a box fabricated from plywood. Figure (2) shows the different locations of opening. Openings were at three different zones; above support, flexural zone which is between two concentrated points load, and shear zone which is between concentrated point load to and close support

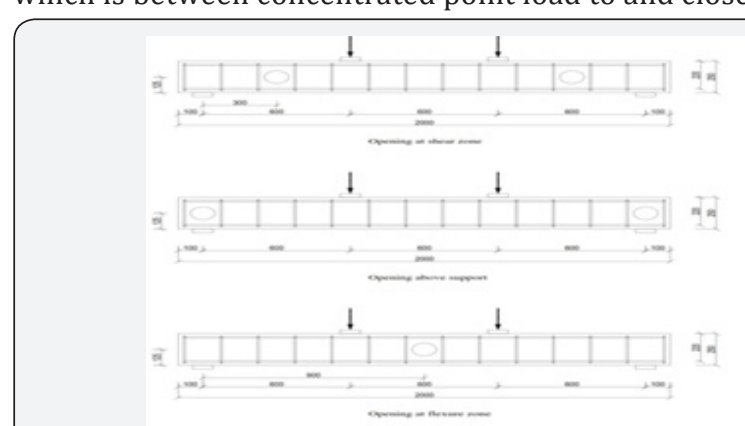

Figure 2: Detail of different locations of opening.

Table 1: Detail of beam specimens.

\begin{tabular}{|c|c|c|c|c|}
\hline \multirow{2}{*}{ Beam Specimen } & \multirow{2}{*}{ Opening Type } & Opening Size & \multirow{2}{*}{$\% \mathrm{H}$} & \multirow{2}{*}{ Zone } \\
\hline & & $(\mathrm{mm})$ & & \\
\hline $\mathrm{BN}$ & $===$ & $====$ & $====$ & $===$ \\
\hline BC-SH-1 & Circular & 140 & 0.56 & Shear \\
\hline BC-SH-2 & Circular & 130 & 0.52 & Shear \\
\hline BC-SH-3 & Circular & 120 & 0.48 & Shear \\
\hline $\mathrm{BC}-\mathrm{SH}-4$ & Circular & 110 & 0.44 & Shear \\
\hline $\mathrm{BC}-\mathrm{SH}-5$ & Circular & 100 & 0.4 & Shear \\
\hline BC-SH-6 & Circular & 80 & 0.32 & Shear \\
\hline BC-SH-7 & Circular & 60 & 0.24 & Shear \\
\hline BC-SH-8 & Circular & 40 & 0.16 & Shear \\
\hline BC-S-1 & Circular & 140 & 0.56 & Above Support \\
\hline BC-S-2 & Circular & 80 & 0.32 & Above Support \\
\hline BC-S-3 & Circular & 40 & 0.16 & Above Support \\
\hline BC-F-1 & Circular & 140 & 0.56 & Flexure \\
\hline BC-F-2 & Circular & 80 & 0.32 & Flexure \\
\hline BC-F-3 & Circular & 40 & 0.16 & Flexure \\
\hline BS-SH-1 & Square & 125 & 0.5 & Shear \\
\hline BS-SH-2 & Square & 80 & 0.32 & Shear \\
\hline BS-SH-3 & Square & 40 & 0.16 & Shear \\
\hline BS-S-1 & Square & 125 & 0.5 & Above Support \\
\hline BS-S-2 & Square & 80 & 0.32 & Above Support \\
\hline BS-S-3 & Square & 40 & 0.16 & Above Support \\
\hline BS-F-1 & Square & 125 & 0.5 & Flexure \\
\hline BS-F-2 & Square & 80 & 0.32 & Flexure \\
\hline BS-F-3 & Square & 40 & 0.16 & Flexure \\
\hline BR-SH-1 & Rectangular & $80 \times 140(h \times b)$ & 0.32 & Shear \\
\hline
\end{tabular}




\section{Civil Engineering Research Journal}

\begin{tabular}{|c|c|c|c|c|}
\hline BR-S-1 & Rectangular & $80 \times 140(\mathrm{~h} \times \mathrm{b})$ & 0.32 & Above Support \\
\hline BR-F-1 & Rectangular & $80 \times 140(\mathrm{~h} \times \mathrm{b})$ & 0.32 & Flexure \\
\hline
\end{tabular}

In order to make it easy to recognize the description of each beam, abbreviation of words had been used. So alphabetic letter "N" will refer to the solid beam without opening; and " $\mathrm{C}, \mathrm{S}$ and $\mathrm{R}$ " will refer to the type of opening that is circular, square and rectangular, respectively. "SH, S and F" will refer to opening zone that is shear, above support and flexural zones, respectively.

\section{Items of investigation}

At the age of 28 days, $\mathrm{RC}$ beam specimens were tested to investigate the effect of size the unreinforced opening on the behavior of concrete beams without additional reinforcement at opening. This experimental study focuses on:

a. The effect of different diameters of circular opening on the behavior of concrete beams at shear zone.

b. The effect of different heights of square opening at different locations. c. The effect of different shapes of opening (circular, square and rectangular) at different locations (flexure zone, shear zone and above support).

d. Comparison between circular opening of $140 \mathrm{~mm}$ in diameter and equivalent area of square opening of $125 \mathrm{~mm}$ in height.

e. Comparison between square opening of $80 \mathrm{~mm}$ in height and rectangular opening of same height.

\section{Experimental Results and Discussion}

The test results are summarized in Table 2. The table shows ultimate failure load $(\mathrm{Pu})$, maximum deflection $(\max )$ and failure modes for all the beam specimens. It was observed that solid beam (BN) deformed less than some beams with circular opening. The deflections of these beams were more both near the opening due to reduction of stiffness of the beam.

Table 2: Test Results.

\begin{tabular}{|c|c|c|c|}
\hline Beam Specimen & Pu (kN) & $\max (\mathbf{m m})$ & Failure Mode \\
\hline $\mathrm{BN}$ & 79.8 & 29.9 & Flexure \\
\hline BC-SH-1 & 35.43 & 16.11 & Shear \\
\hline BC-SH-2 & 46.7 & 20.36 & Shear \\
\hline BC-SH-3 & 58.45 & 24.63 & Shear \\
\hline BC-SH-4 & 70.22 & 28.77 & Flexure \\
\hline BC-SH-5 & 78.52 & 31.44 & Flexure \\
\hline BC-SH-6 & 79 & 30.61 & Flexure \\
\hline BC-SH-7 & 79.15 & 30.07 & Flexure \\
\hline BC-SH-8 & 79.5 & 29.95 & Flexure \\
\hline BC-S-1 & 49.45 & 22.48 & Shear \\
\hline BC-S-2 & 79.28 & 30.72 & Flexure \\
\hline BC-S-3 & 79.64 & 30.24 & Flexure \\
\hline BC-F-1 & 73.31 & 33.33 & Flexure \\
\hline BC-F-2 & 79.68 & 30.87 & Flexure \\
\hline BC-F-3 & 79.76 & 30.01 & Flexure \\
\hline BS-SH-1 & 28.94 & 12.39 & Shear \\
\hline BS-SH-2 & 52.15 & 20.2 & Shear \\
\hline BS-SH-3 & 67.03 & 25.22 & Flexure \\
\hline BS-S-1 & 55.58 & 23.8 & Flexure \\
\hline BS-S-2 & 65.88 & 25.53 & Flexure \\
\hline BS-S-3 & 74.09 & 28 & Flexure \\
\hline BS-F-1 & 71.48 & 30.94 & Flexure \\
\hline BS-F-2 & 74.92 & 29.03 & Flexure \\
\hline BS-F-3 & 77.89 & 29.31 & Flexure \\
\hline BR-SH-1 & 49.11 & 19.03 & Shear \\
\hline BR-S-1 & 63.44 & 24.58 & Flexure \\
\hline BR-F-1 & 72.43 & 28.06 & Flexure \\
\hline
\end{tabular}




\section{Effect of circular opening sizes at shear zone}

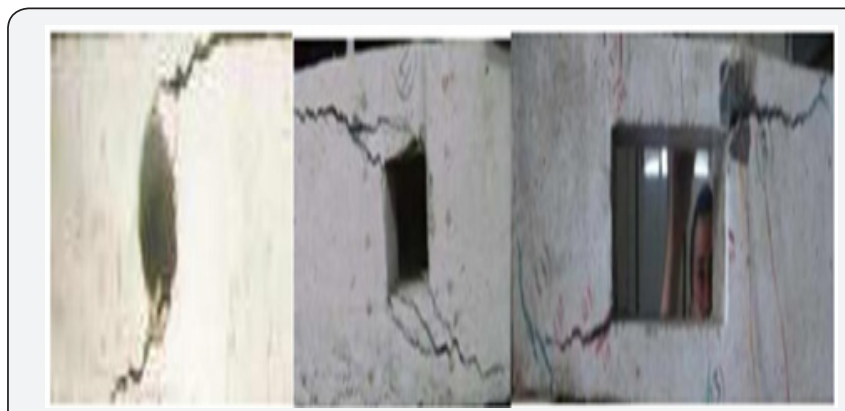

Figure 3: Mode of failure of specimens.

To study the effect of different sizes for circular opening, the position of the applied load was kept constant and the distance from the support to the opening for both sides of the beam was taken as $300 \mathrm{~mm}$. (Figures $3 \& 4$ ) show comparison of beam specimens in this section. The test results showed there is a slight difference between beams with opening and control beam till opening size of $100 \mathrm{~mm}(0.4 \mathrm{H})$. Increasing opening size than $100 \mathrm{~mm}(0.4 \mathrm{H})$, the ultimate load decreased significantly. So the opening with size less than $(0.4 \mathrm{H})$ was considered as small opening; otherwise, was considered as large opening.

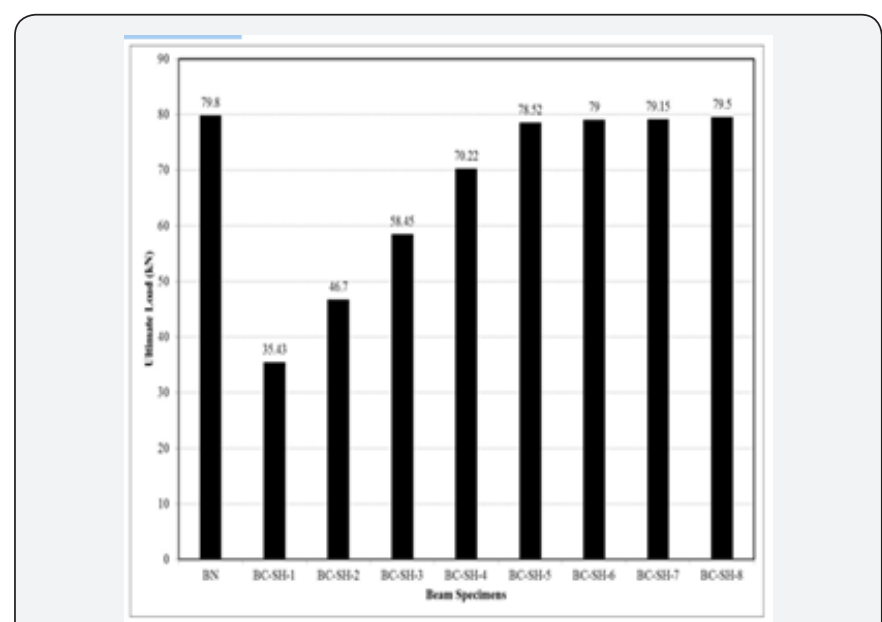

Figure 4: Effect of circular opening size on ultimate failure load.

Effect of square opening sizes at different zones

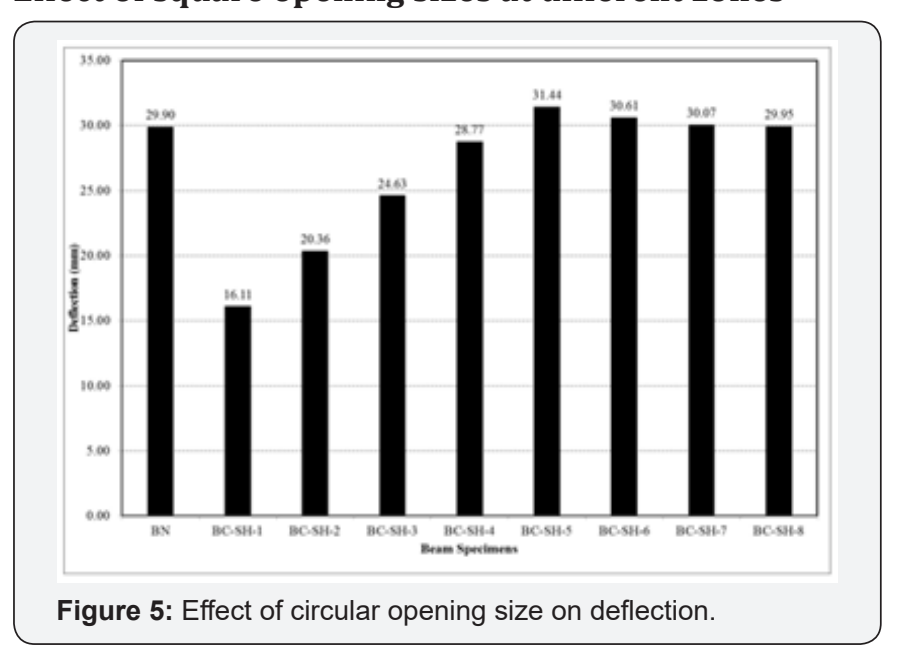

To study the effect of square opening sizes, sizes of 40,80 and $140 \mathrm{~mm}$ at different zones was investigated. (Figures $5 \& 6$ ) show the comparison of beam specimens in this section. The test results showed that providing a square opening of $40 \mathrm{~mm}(0.16 \mathrm{H})$ caused average reduction in ultimate load about (9\%), while size of $80 \mathrm{~mm}(0.32 \mathrm{H})$ caused average reduction about $(19 \%)$ but a rectangular opening caused average reduction about (35\%). When opening located at the shear zone causes sharp decrease in the ultimate load about (38\%) and when opening is located above the supports the average reduction was about (18\%) but at flexure zone showed the minimum effect where the average reduction was $(6 \%)$.

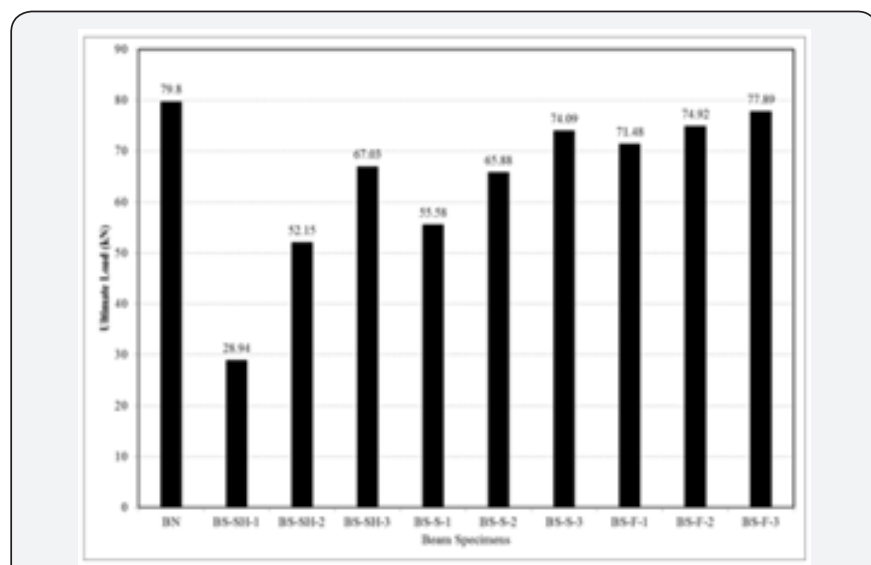

Figure 6: Effect of square opening at different zones on ultimate failure load.

\section{Effect of different opening shapes at different zones}

To study the effect of different opening shapes, size of $80 \mathrm{~mm}$ at different zones was investigated. (Figures $7 \& 8$ ) show the comparison of beam specimens in this section. The test results showed that providing a circular opening caused average reduction in ultimate load about (1\%), while a square opening caused average reduction about (19\%) but a rectangular opening caused average reduction about (23\%). When opening located at the shear zone causes sharp decrease in the ultimate load about (25\%) and when opening is located above the supports the average reduction was about $(13 \%)$ but at flexure zone showed the minimum effect where the average reduction was (5\%).

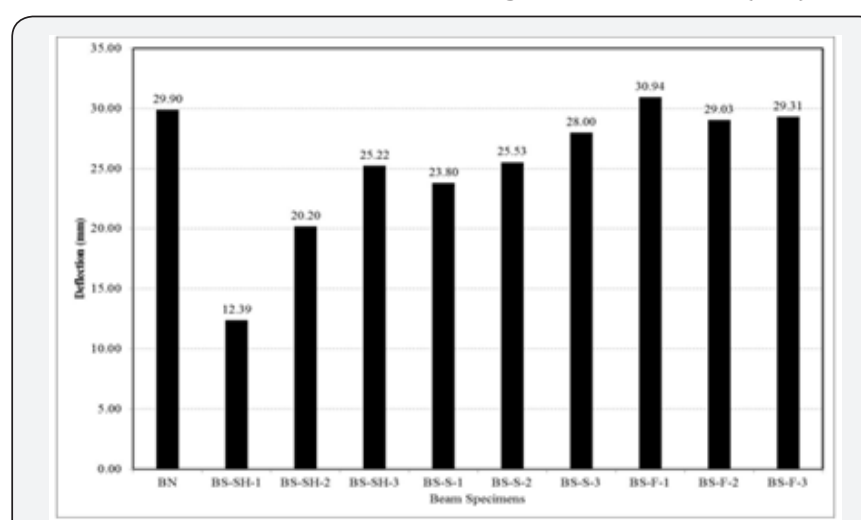

Figure 7: Effect of square opening at different zones on deflection. 


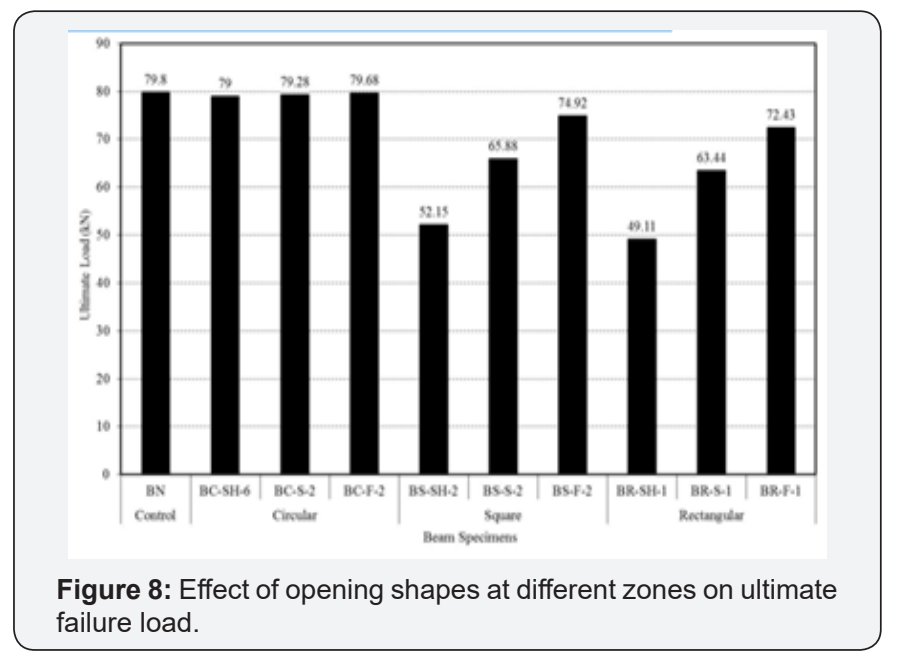

\section{Comparison between circular opening and equivalent} area of square opening

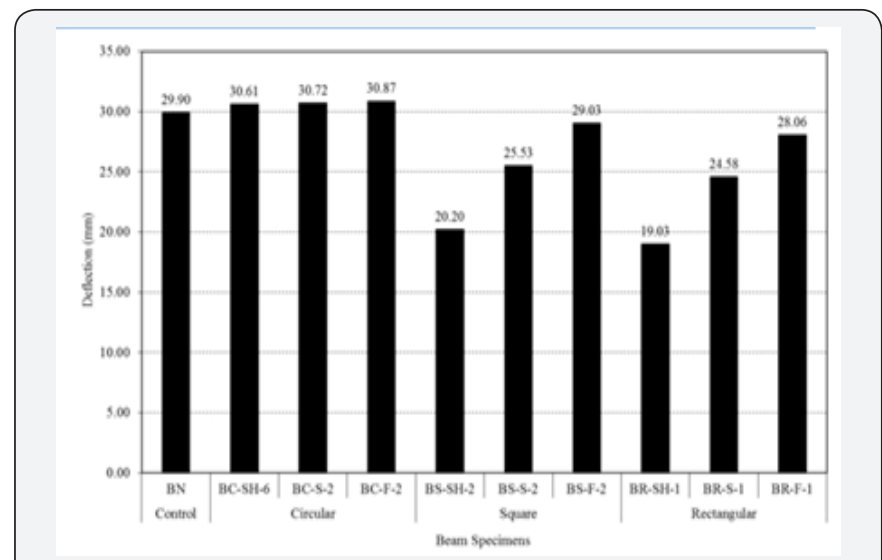

Figure 9: Effect of opening shapes at different zones on deflection.

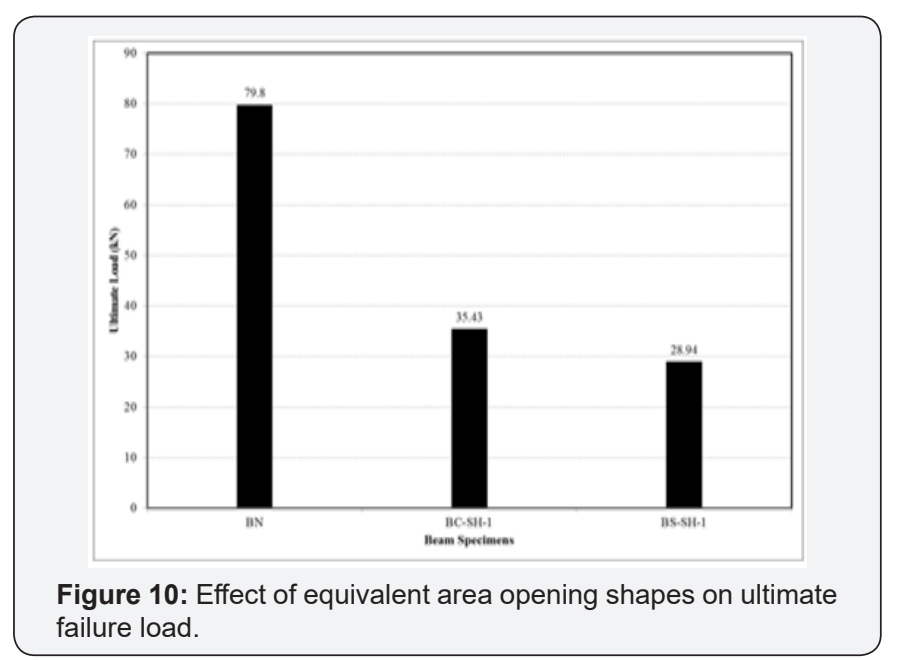

In this part circular opening of $140 \mathrm{~mm}$ in diameter and square opening of $125 \mathrm{~mm}$ in height with same area were studied. (Figures 9 \& 10) show the comparison of beam specimens of this section. The test results showed that providing a square opening caused reduction in ultimate load about (8\%) more than circular opening. The reason behind that reduction in square opening is that the existing orthogonal corners caused more stress concentration at these corners. Sudden change in the dimension of cross section of the leaded to high stress concentration at the corners of square opening that may lead to undesirable cracks.

\section{Comparison between square opening and rectangular opening of same height}

In this part square openings of $80 \mathrm{~mm}$ in height and rectangular openings with same height were studied. (Figures 11 \& 12) show the comparison of beam specimens of this section. The test results showed that providing an opening, a rectangular opening caused reduction in ultimate load about (3$4 \%$ ) more than square opening. The shear stresses developed in the top and bottom chords at rectangular opening, which that we considered the beam act like a frame.

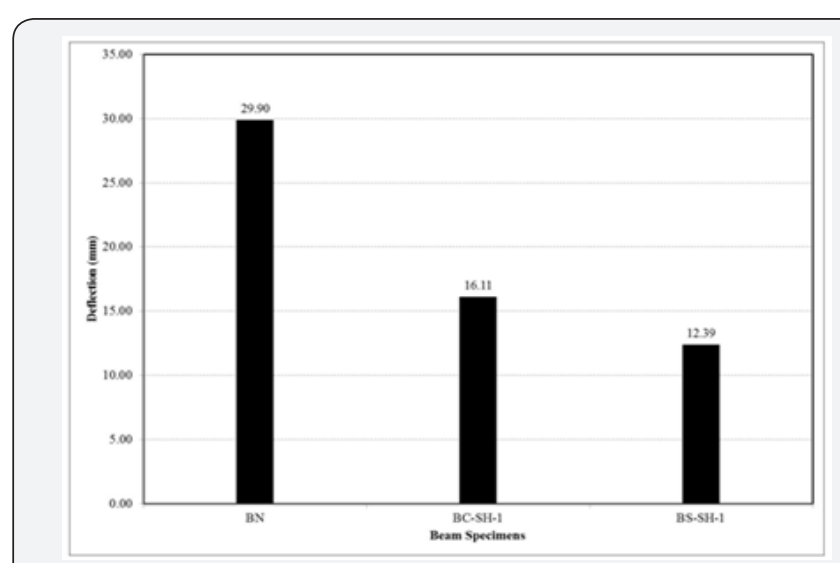

Figure 11: Effect of equivalent area opening shapes on deflection.

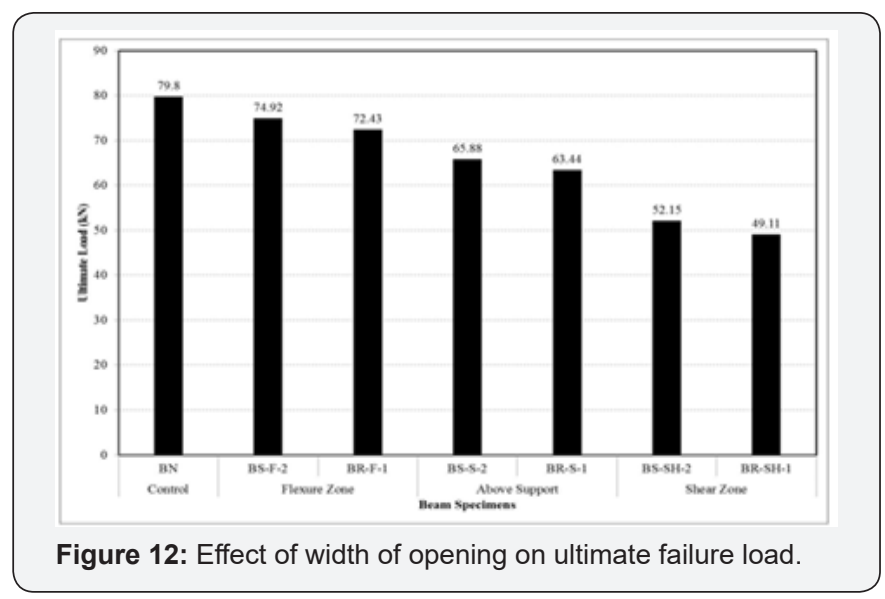

Further Research

a. Studying the shear strength of concrete deep beams with openings can be carried out by modifying the material.

b. Studying strengthening opening by web reinforcement.

c. Studying strengthening opening by new materials as steel fiber or FRP laminates and different configurations.

d. Study behavior of deep beam with openings using different concrete types such as high strength concrete 


\section{Civil Engineering Research Journal}

\section{Conclusion}

Based on the results of this experimental investigation, it could be concluded that:

a. The location of openings has a large effect, where this effect is the large0073t when openings location is at shear zone and a small effect when openings location is at flexure zone, so the best place for the location of opening in these beams is in middle of a beam.

b. Circular opening is the best shape of opening that showed the least reduction in ultimate load.

c. In RC beams with small opening at flexure zone, the maximum reduction in ultimate load was about (1.5\%).

d. In RC beams with large opening at flexure zone, excessive flexural cracks were found at the tension zone around the openings. The failure mode was in flexure. Providing large opening in RC beam decreased the ultimate load about (10\% max.). However, in terms of deflection, the beam deflection increased by (11\% max.) more than the control beam.

e. In RC beams with small opening at shear zone, the maximum reduction in ultimate load was about (2.5\%).

f. In RC beams with large opening at shear zone, excessive shear cracks were found around the openings. The failure mode was in shear. Providing large opening in RC beam decreased the ultimate load about (64\% max.). However, in terms of deflection, the beam deflection decreased by $(57 \%$ max.) more than the control beam.

\section{References}

1. Mansur MA, Tan KH (2013) Concrete Beams with Openings: Analysis and Design. CRC Press, Florida, USA.
2. Allam SM (2005) Strengthening of RC beams with large openings in the shear zone. Alexandria Engineering Journal 44(1): 59-78.

3. Mansur MA (1998) Effect of Openings on the Behavior and Strength of R/C Beams in Shear. Cement and Concrete Composites 20: 477-486.

4. Soroush A, Masoudnia R, Akbar AP (2014) The Study of the Effects of Web Openings on the Concrete Beams. Australian Journal of Basic and Applied Sciences 5(7): 547-556.

5. Niea JG, Caib CS, Wua H, Fana JS (2006) Experimental and Theoretical Study of Steel-Concrete Composite Beams With Openings in Concrete Flange. Engineering Structures 28: 992-1000.

6. El-Maaddawy T, El-Ariss B (2013) Investigation into the performance of concrete beams with rectangular openings strengthened in shear with CFRP composites.

7. Subhajit M, Bandyapadhya JN, Gautam CP (2016) Strengthening and Rehabilitation of Reinforced Concrete Beams with opening. Civil Engineering Department, IIT Kharagpur, India. International Journal of civil and Structural Engineering 2(1): 0976- 4399.

8. Soroush A and Masoudnia R (2015) Investigation of the Opening Effects on the Behaviour of Concrete Beams without Additional Reinforcement in Opening Region Using Fem Method. Australian Journal of Basic and Applied Sciences 5 (5): 617-627.

9. Somes NF, Corley WG (1974) Circular openings in webs of continuous beams. American Concrete Institute, Farmington Hills Mich 42: 359398.

10. Lee JK, Li CG, Lee YT (2008) Experimental Study on Shear Strength on Reinforced Concrete Continuous Deep Beams with Web Opening. The $14^{\text {th }}$ World Conference on Earthquake Engineering, Beijing, china.

\section{Your next submission with Juniper Publishers} will reach you the below assets

- Quality Editorial service

- Swift Peer Review

- Reprints availability

- E-prints Service

- Manuscript Podcast for convenient understanding

- Global attainment for your research

- Manuscript accessibility in different formats

( Pdf, E-pub, Full Text, Audio)

- Unceasing customer service

Track the below URL for one-step submission https://juniperpublishers.com/online-submission.php 